\title{
Perivascular epithelioid cell tumour of the uterus: what do we know?
}

\author{
Yvonne W. Y. Wong*, Julian H. L. Kang
}

Department of Obstetrics and Gynecology, K. K. Women's and Children's Hospital, Singapore

Received: 04 September 2020

Revised: 19 October 2020

Accepted: 27 October 2020

\section{*Correspondence:}

Dr. Yvonne W. Y. Wong,

E-mail: yvonne.wong@mohh.com.sg

Copyright: (c) the author(s), publisher and licensee Medip Academy. This is an open-access article distributed under the terms of the Creative Commons Attribution Non-Commercial License, which permits unrestricted non-commercial use, distribution, and reproduction in any medium, provided the original work is properly cited.

\begin{abstract}
Perivascular epithelioid cell neoplasm (PEComa) is a rare mesenchymal tumour characterized by distinctive histological and immunohistochemical perivascular epithelioid cells. These tumours can be found in various anatomic sites, with gynaecologic PEComas accounting for nearly one-fourth of reported cases in the literature. However, due to its nonspecific clinical presentation and a lack of definitive radiological appearance, the diagnosis of PEComas remains challenging. In this case report, we describe a 45-year old lady suffering from urinary retention secondary to large uterine fibroids, who then underwent a total hysterectomy. Postoperative histopathology with immunohistochemical stains confirmed an unexpected finding of uterine PEComa. Although the treatment of gynaecologic PEComas remains controversial, complete surgical resection with negative margins is recommended. A multidisciplinary approach will be beneficial in determining the necessity of adjuvant therapy such as targeted therapy with mTOR inhibitors, especially for PEComas which exhibit aggressive and high-risk features.
\end{abstract}

Keywords: Perivascular epithelioid cell, PEComa, Uterus, Gynaecologic, mTOR inhibitors

\section{INTRODUCTION}

Perivascular epithelioid cell tumours (PEComa) are a rare group of mesenchymal neoplasms characterized by distinctive histological and immunohistochemical perivascular epithelioid cells. ${ }^{1}$ PEComas can occur at any anatomic site and include angiomyolipomas, lymphangioleiomyomatosis, clear cell "sugar" tumours of the lung, and PEComa not otherwise specified. ${ }^{2}$ Due to its non-specific clinical presentation and a lack of definitive radiological appearance, the diagnosis of PEComas remains challenging. Here, we report a case of a 45-yearold lady who underwent hysterectomy for large fibroids with an incidental histological diagnosis of PEComa.

\section{CASE REPORT}

A 45-year old lady with no notable medical history was referred to our centre for an incidental finding of uterine fibroids found on computerized tomography intravenous pyelography (CT IVP). She had no menstrual complaints and was initially seen by the urology team for recurrent episodes of acute urinary retention for which CT IVP was ordered for further evaluation.

CT IVP revealed large fibroids, with the uterus displacing the bladder and indenting upon its posterior-superior wall. There were also multiple large cystic structures demonstrated in the right ovary, largest measuring $3.3 \times 2.8$ $\mathrm{cm}$.

Ultrasound (US) pelvis reported an endometrial thickness of $15 \mathrm{~mm}$ with small avascular echogenic nodules in the endometrium, possibly representing endometrial polyps. There were a few uterine fibroids, largest measuring $10.0 \times 8.5 \times 9.4 \mathrm{~cm}$. An $8.4 \times 4.6 \times 5.4 \mathrm{~cm}$ right adnexal multiloculated cystic avascular structure is noted with internal echoes and septations. Ovarian tumour markers (cancer antigen 125, beta human chorionic gonadotropin, carcinoembryonic antigen and alpha-fetoprotein) 
performed were normal. Thereafter, our patient underwent hysteroscopy, dilatation and curettage which was normal.

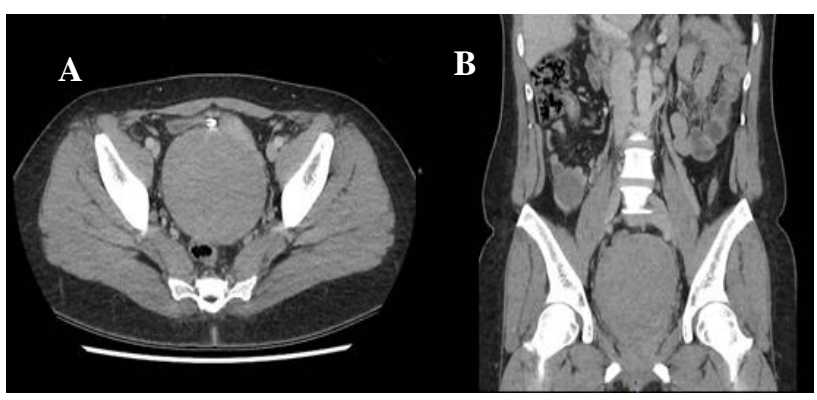

Figure 1: (A) and (B) CT IVP images showing a large homogeneous hypodense circumscribed mass arising from the posterior wall of the anteverted uterus which may represent a fibroid $(9.4 \times 8.5 \times 10.0 \mathrm{~cm})$.

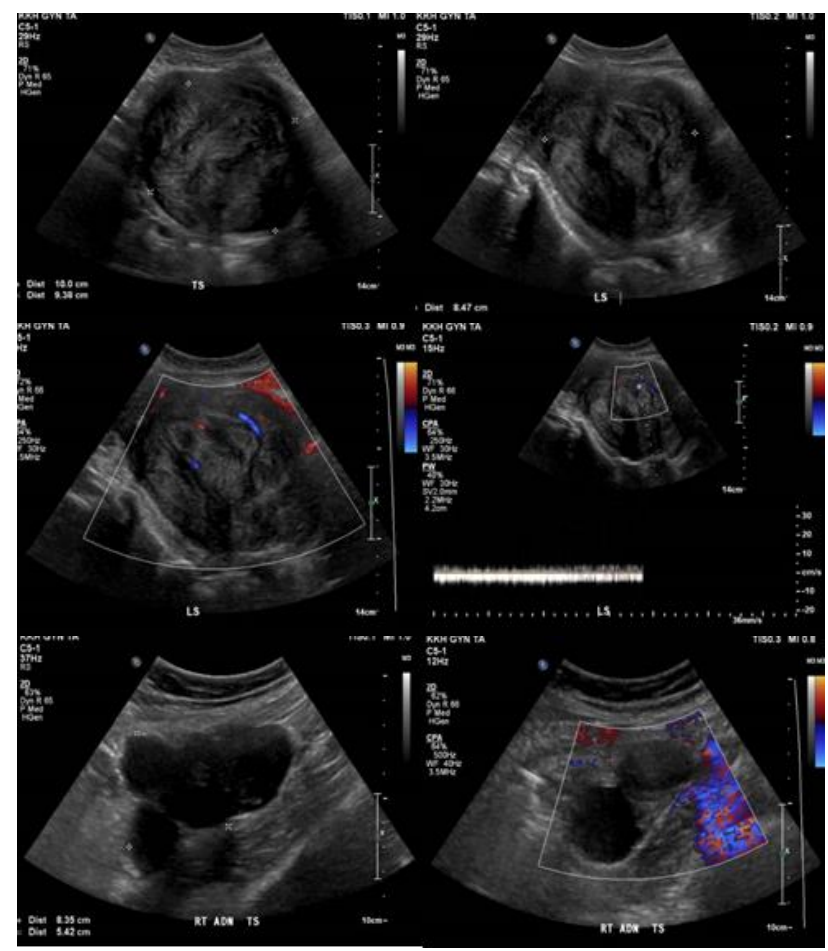

Figure 2: (a-d) Ultrasound pelvis images showing multiple fibroids, largest $10.0 \times 8.5 \times 9.4 \mathrm{~cm}$ in the posterior wall of uterus; and (e) and (f) $8.4 \times 4.6 \times 5.4$ $\mathrm{cm}$ right adnexal multiloculated cystic avascular structure with internal echoes and septations.

Ovarian tumour markers (cancer antigen 125, beta human chorionic gonadotropin, carcinoembryonic antigen and alpha-fetoprotein) performed were normal. Thereafter, our patient underwent hysteroscopy, dilatation and curettage which was normal.

In view of her repeated urinary retention episodes, she opted for surgical intervention. A total abdominal hysterectomy right salpingo-oophorectomy and left salpingectomy was performed. Operative findings revealed a 6 -week sized uterus with a $12 \mathrm{~cm}$ posterior lower segment fibroid displacing the cervix. There was an $8 \mathrm{~cm}$ multiloculated cystic right ovarian mass, which was reported as having haemorrhagic and endometriotic contents with no overt malignancy on frozen section analysis. The right tube, left tube and left ovary appeared normal.

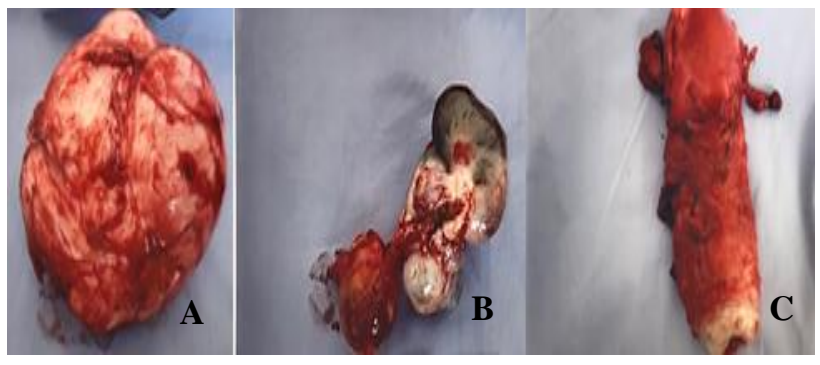

Figure 3: Intraoperative photos (A) large posterior wall fibroid, (B) right ovarian mass, and (C) uterus, cervix and left tube.

Final histopathology reported a uterine epithelioid and spindle cell neoplasm with pleomorphism, $1.2 \mathrm{~cm}$ in greatest dimension. There were no mitoses, lymphovascular invasion nor necrosis, thus favouring a benign perivascular epithelioid cell neoplasm (PEComa). Immunohistochemical stains were positive for human melanoma black 45 (HMB-45) and Melan A.

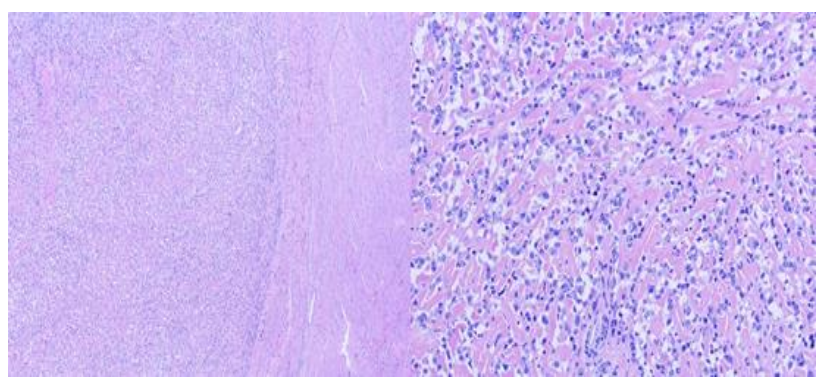

Figure 4: Uterine tumour composed of perivascular epithelioid cells arranged in solid nests or sheets with moderate to severe nuclei pleomorphism and abundant cytoplasm that varied from eosinophilic and granular to clear.

In view of the association between PEComas and tuberous sclerosis complex (TSC), our patient was referred to the genetics team for further evaluation. However, she defaulted the appointment due to financial concerns. She is currently on surveillance and remains asymptomatic. Her 18-month post-operative pelvic scan showed the presence of a $2.4 \mathrm{~cm}$ left endometriotic ovarian cyst.

\section{DISCUSSION}

Perivascular epithelioid cell neoplasms (PEComas) are rare mesenchymal tumours which are composed of histologically and immunohistochemically distinctive perivascular epithelioid cells. To date, there are 114 gynaecological tract PEComas reported worldwide. Of 
which, the most affected anatomic sites include the uterus $(58.6 \%)$, followed by the cervix $(10.5 \%) .{ }^{3}$ The lack of specific clinical and imaging characteristics makes the diagnosis of PEComas challenging. Therefore, definitive diagnosis is made based on a combination of histological and immunohistochemical analysis.

The hallmarks of PEComa are as follows: the presence of an epithelioid appearance, which is characterized by a clear to eosinophilic and granular cytoplasm, with centrally located, round to oval nuclei with a nucleolus. ${ }^{4}$ The tumour cells typically grow in nests or sheets and are usually around or perpendicular to blood vessels. ${ }^{5}$

Immunohistochemically, a perivascular epithelioid cell is characterized by positivity for melanocytic markers, such as HMB-45, melan-A, tyrosinase, microphthalmia transcription factor, and $\mathrm{NKI} / \mathrm{C} 3$, and smooth muscle markers, such as smooth muscle actin, desmin, hcaldesmon, pan-muscle actin, muscle myosin and calponin. $^{6-8}$

PEComas are classified into benign, uncertain malignant potential and malignant based on the presence of worrisome features. PEComas that do not possess any of the worrisome features are benign. Tumours of uncertain malignant potential are defined as having only either nuclear pleomorphism/multinucleated giant cells or are more than $5 \mathrm{~cm}$ in size. PEComas which are malignant will exhibit two or more worrisome features. ${ }^{9}$

There is no unanimous consensus on treatment due to the small number of reported gynaecological tract PEComas and lack of randomized controlled trials. At present, the recommended mainstay of treatment is complete surgical resection with the aim of negative margins. ${ }^{10-13}$ A complete resection is of paramount importance to evaluate the tumour for histopathologic prognostic risk factors. ${ }^{14}$ The role of adjuvant therapy such as chemotherapy and radiotherapy remains unclear.

PEComas are rare and often, sporadic. However, $10 \%$ of PEComas can be associated with tuberous sclerosis complex (TSC). TSC affects 1 in 6000 people. ${ }^{15}$ It is an autosomal dominant genetic condition characterized by the growth of numerous benign tumours in many parts of the body- most commonly, the brain, kidneys, heart, eyes, lungs and skin.

Depending on the location of the tumours, symptoms can range from mild to severe and commonly includes a combination of seizures, autism, impaired intellectual development, behavioural problems, skin abnormalities and kidney disease.

Table 1: Folpe criteria for classification of PEComas.

\begin{tabular}{|c|c|c|c|}
\hline & Benign & $\begin{array}{l}\text { Uncertain malignant } \\
\text { potential }\end{array}$ & Malignant \\
\hline \multirow{6}{*}{ Criteria } & Size $<5 \mathrm{~cm}$ & \multirow{6}{*}{$\begin{array}{l}\text { Nuclear pleomorphism/ } \\
\text { multinucleated giant } \\
\text { cells only } \\
\text { Or, Size }>5 \mathrm{~cm} \text { only }\end{array}$} & Size $>5 \mathrm{~cm}$ \\
\hline & Non-infiltrative & & Infiltrative \\
\hline & Non-high nuclear grade and cellularity & & High nuclear grade and cellularity \\
\hline & Mitotic rate $\leq 1 / 50$ high power fields & & Mitotic rate $\geq 1 / 50$ high power fields \\
\hline & No necrosis & & Necrosis \\
\hline & No vascular invasion & & Vascular invasion \\
\hline
\end{tabular}

The role of targeted therapy comes about due to PEComas' possession of mutated TSC 1 (9q34) and TSC 2 (16p13.3) genes, which affects the production of proteins hamartin and tuberin respectively.16,17 TSC1 and TSC 2 genes interact as heterodimers that inhibit the mammalian target of rapamycin (mTOR) pathway, affecting cellular growth and protein synthesis. ${ }^{18,19}$ mTOR inhibitors, such as Sirolimus, have shown promising results in recent case reports, and should be considered based on the behaviour of tumour and the presence of high-risk features

\section{CONCLUSION}

Gynaecological PEComa is a rare pathology with nonspecific clinical presentation and radiological appearances, therefore making its diagnosis and management challenging. The clinical outcome of PEComa is variable and depends on the presence of high-risk histological features. Although there is no consensus on the management of PEComa, complete surgical resection with negative margins remains the cornerstone of therapy. The addition of targeted therapy should be considered in patients with high-risk features.

\section{Funding: No funding sources \\ Conflict of interest: None declared \\ Ethical approval: Not required}

\section{REFERENCES}

1. Folpe AL. Neoplasms with perivascular epithelioid cell differentiation (PEComas). In: Fletcher CDM, Unni KK, Mertens F, eds. Pathology and Genetics of Tumors of Soft Tissue and Bone. Lyon, France: IARC Press. 2002;221-2.

2. Pea M, Martignoni G, Zamboni G, Bonetti F. Perivascular epithelioid cell. Am J Surg Pathol. 1996;20:1149-53. 
3. Liu C, Chao W, Lin S, Lau $\mathrm{H}$, Wu H, Wang $\mathrm{P}$. Malignant perivascular epithelioid cell tumour in the female genital tract. Medicine. 2019;98:14072.

4. Folpe AL, Mentzel T, Lehr HA, Fisher C, Balzer BL, Weiss SW, et al. Perivascular epithelioid cell neoplasms of soft tissue and gynecologic origin: a clinicopathologic study of 26 cases and review of the literature. Am J Surg Pathol. 2005;29:1558-75.

5. Fitzpatrick M, Pulver T, Klein M, Murugan P, Khalifa M, Amin K. Perivascular epithelioid cell tumor of the uterus with ovarian involvement: a case report and review of the literature. Am J Case Rep. 2016;17:30914.

6. Theofanakis C, Thomakos N, Sotiropoulou M, Rodolakis A. Perivascular epithelioid cell tumor of the uterus: report of two cases and mini-review of the literature. Int J Surg Case Rep. 2016;28:85-7.

7. Fadare O. Perivascular epithelioid cell tumor (PEComa) of the uterus: an outcome-based clinicopathologic analysis of 41 reported cases. Adv Anat Pathol. 2008;15:63-75.

8. Fadare O. Uterine PEComa: appraisal of a controversial and increasingly reported mesenchymal neoplasm. ISSO. 2008;5:7.

9. Westaby JD, Magdy N, Fisher C, El-Bahrawy M. Primary ovarian malignant PEComa: a case report. Int J Gynecol Pathol. 2017;36:400-4.

10. Schoolmeester JK, Howitt BE, Hirsch MS, Dal Cin P, Quade BJ, Nucci MR, et al. Perivascular epithelioid cell neoplasm (PEComa) of the gynecologic tract: clinicopathologic and immunohistochemical characterization of 16 cases. Am J Surg Pathol. 2014;38:176-88.

11. Davies DM, de Vries PJ, Johnson SR, McCartney DL, Cox JA, Serra AL, et al. Sirolimus therapy for angiomyolipoma in tuberous sclerosis and sporadic lymphangioleiomyomatosis: a phase 2 trial. Clin Cancer Res. 2011;17:4071-81.
12. Szpurek D, Szubert S, Zielinski P, Frankowski A, Sajdak S, Moszynski R. Malignant presentation of uterine lymphangioleiomyomatosis. Taiwan J Obstet Gynecol. 2015;54:603-7.

13. Liu J, Meng T, Yang X, Zhao G, Li B. Spontaneous rupture of renal angiomyolipoma in the third trimester. Taiwan J Obstet Gynecol. 2015;54:788-90.

14. Rothenberger R, Jackson A, Kendler A, Herzog T, Billingsley C. An unusual case of uterine PEComa presenting with disseminated intravascular coagulation. Gynecol Oncol Rep. 2019;29:76-8.

15. National Library of Medicine. Tuberous sclerosis complex. 2020. Available at: https://ghr.nlm.nih.gov/condition/tuberous-sclerosiscomplex\#statistics. Accessed on 10 June 2020.

16. The European Chromosome 16 Tuberous Sclerosis Consortium. Identification and characterization of the tuberous sclerosis gene on chromosome 16. Cell. 1993;75:1305-15.

17. Van Slegtenhorst M, de Hoogt R, Hermans C, Nellist $M$, Janssen B, Verhoef S, Lindhout D, et al. Identification of the tuberous sclerosis gene TSC1 on chromosome 9q34. Science. 1997;277:805-8.

18. Gao S, Wang Z, Xie Y. Two novel TSC2 mutations in pediatric patients with tuberous sclerosis complex: case report. Medicine (Baltimore). 2018;97:11533.

19. Gu X, Han L, Chen J, Wang J, Hao X, Zhang Y, et al. Antenatal screening and diagnosis of tuberous sclerosis complex by fetal echocardiography and targeted genomic sequencing. Medicine (Baltimore). 2018;97:0112.

Cite this article as: Wong YWY, Kang JHL. Perivascular epithelioid cell tumour of the uterus: what do we know?. Int J Reprod Contracept Obstet Gynecol 2020;9:5110-3. 